\section{Edycaçäa

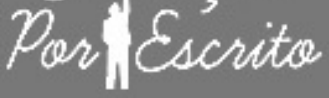

ARTIGO

\section{Editor}

Maria Inês Côrte Vitoria PUCRS, RS, Brasil

\section{Equipe Editorial}

Pricila Kohls dos Santos PUCRS, RS, Brasil

Marcelo Oliveira da Silva PUCRS, RS, Brasil

Carla Spagnolo

PUCRS, RS, Brasil

Rosa Maria Rigo

PUCRS, RS, Brasil

\section{ISSN 2179-8435}

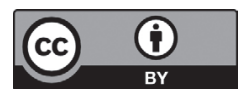

Este artigo está licenciado sob forma de uma licença Creative Commons Atribuição 4.0 Internacional, em qualquer meio, desde qustribuição e reproduçào seja corretamente citada. http://creativecommons.org/licenses/by/4.0/deed.pt_BP

\title{
Representações de gênero e literatura infantil: paradidáticos em análise
}

\author{
Representations of gender and children's literature: paradidatics books under review
}

\section{Fábio Soares da Costa ${ }^{a}$, Andreia Mendes dos Santos ${ }^{b}$}

RESUMO: A adoção de livros paradidáticos para a educação infantil é uma prática identificada na maioria das escolas brasileira, pois é útil como uma estratégia de ação educativa, visando uma complementaridade das temáticas dos livros didáticos. Neste contexto, analisamos quatro livros paradidáticos: Os músicos de Bremen (Ruth Rocha); Uma trança dourada (Tatiana Belinky); A rainha rabiscada (Sylvia Orthof); e O pavão abre e fecha (Ana Maria Machado). Optamos, teórico-metodologicamente, pela a análise do discurso crítica, a partir Norman Fairclough (2001), Eliseo Verón (2004) e Laerte Magalhães (2003), e objetivamos identificar as representações e discursos de gênero construídas nessa literatura. Assim, observamos a existência de esteriotipais de dualização entre os sexos, um modelo patriarcal, romantismo e estetização corporal.

Palavras-chave: ACD; educação; gênero; literatura infantil; paradidáticos.

ABSTRACT: The adoption of paradidatics books for early childhood education is a practice identified in most brazilian schools, it is useful as an educational action strategy, seeking complementarities of themes from didatics. In this context, analyzed four paradidatics books: Musicians of Bremen (Ruth Rocha); A golden braid (Tatiana Belinky); The scrawled queen (Sylvia Orthof); and Peacock opens and closes (Ana Maria Machado). We decided, theoretically and methodologically by the analysis of critical discourse, from Norman Fairclough (2001), Eliseo Verón (2004) and Laerte Magalhães (2003), and aimed to identify the representations and gender discourses built this literature. Thus, we observe the existence of esteriotipais of duality between the sexes, patriarchal model, romanticism and body aestheticization.

Keywords: ACD; education; gender; children's literature; paradidatics.

a Doutorando em Educação pelo PPGEdu da Escola de Humanidades da PUCRS. Mestre em Comunicação pelo PPGCOM/ UFPI. Especialista em Supervisão Escolar pela UFRJ e Licenciado em Educação Física pela UFPI. Membro do Grupo de Estudos e Pesquisa sobre Questões Sociais na Escola. Professor do Curso de Educação Física da Faculdade do Médio Parnaíba - FAMEP e das secretarias de educação dos estados do Piauí e Maranhão.

- Doutora, Professora da Escola de Humanidades e do PPGEdu da Pontifícia Universidade Católica do Rio Grande do Sul - PUCRS. Formada em Psicologia (PUCRS/1995), com Mestrado (PUCRS/2003) e Doutorado em Serviço Social (PUCRS/ 2007). 


\section{Introdução}

relação entre educação, escola e literatura é intensa, produtora de sentidos e transformadora da sociedade em

suas mais diversas facetas. Por isso, percebemos a importância da leitura e, sobretudo, da leitura literária nos mais diversos momentos de nossa vida, inclusive na formação básica, na infância, na escola.

Lajolo (2008) trata da essencialidade da leitura literária reportando-a como instituição, lugar do imaginário, de valores simbólicos e de exercício da cidadania, daí sua importância no currículo escolar, seja na forma didática, quanto recreativa, seja nas publicações impressas, quanto na tradição oral, para todos os níveis de ensino, pois certamente corresponderá à subjetividade da criança, à nutrição psíquica de seus anseios.

Percebemos que as diferenças de gênero representadas em plataformas literárias ajudam a naturalizar divisões e desigualdades, por isso, compreender o conceito de gênero como condição social e não como dicotomia biológica é tão interessante e instigante do ponto de vista da pesquisa científica. A forma como as diferenças sexuais são apresentadas e valorizadas num dado momento histórico é o que importa, pois o gênero é uma ferramenta analítica política e social que procura superar os determinismos da biologia, valorizando as relações entre os seres.

Louro (2003) já alertava para a problematização da naturalização das relações de gênero dentro das práticas pedagógicas, pois as (de)limitações das práticas sociais relacionadas ao fato de serem meninos ou meninas dá-se sobremaneira no ambiente escolar. É por isso que não devemos desconsiderar que o lugar social da menina como tímida, frágil, romântica, recatada, singela, vaidosa, dependente e passiva, e do menino como independente, agressivo, conquistador, rude, frio, intelectual, provedor e autoridade é construído, também, na prática pedagógica, podendo ser identificados em livros de diversos gêneros, como os paradidáticos de educação infantil.

A educação sexista constrói e espera o desenvolvimento de papéis sociais por parte de meninos e meninas compatíveis com a dualização entre os sexos, que precisa do casamento, da reprodução, da vida familiar doméstica já definida historicamente e dos padrões esteriotipais de comportamentos próprios de homem e de mulher.

O objetivo deste estudo se põe sobre a identificação de sentidos de gênero na literatura infantil, bem como da necessidade de verificação das estratégicas discursivas da literatura infantil quanto à abordagem e organização de sentidos relacionados ao gênero. Para isso, analisamos quatro livros paradidáticos: Os músicos de Bremen (Ruth Rocha); Uma trança dourada (Tatiana Belinky); A rainha rabiscada (Sylvia Orthof); e O pavão abre e fecha (Ana Maria Machado), todos esses adotados no ano de 2014 pela Escola Santa Helena, instituição escolar privada de educação infantil, ensino fundamental e médio, em Teresina, no estado do Piauí. A opção 
teórico-metodológica para a análise discursiva dessa literatura foi alicerçada na análise do discurso crítica, a partir das contribuições de Norman Fairclough (2001), Eliseo Verón (2004) e Laerte Magalhães (2003), numa discussão que envolve os aspectos enunciativos e discursivos dos textos/imagens encontrados nesses livros paradidáticos.

Investigamos as principais representações construídas por meio dos sentidos sobre gênero, identificados em paradidáticos de educação infantil, analisando as dizibilidades e invisibilidades proporcionadas pela literatura infantil quanto às relações de gênero. Dessa forma, destacamos a existência de esteriotipais de naturalização da dualidade entre os sexos, com uma padronização tradicional e patriarcal de família, mas com momentos de empoderamento feminino, estetização corporal e romantismo nos relacionamentos amorosos.

\section{Literatura, prática pedagógica e educação infantil}

Os livros paradidáticos são um lugar mágico de desvelamentos, contudo, informam, formam e imprimem estetizações e modalidades comportamentais que podem ser revestidas ou revertidas em padrões de ser, estar e se comportar. Como lugar de imaginação, os livros conformam parte do mundo da criança. Ao lê-los, a criança mixa seu imaginário com o imaginário pretendido no livro e passa a adota-lo como lugar de prazer, onde pode encontrar o mundo perfeito, bastando para isso, explorá-lo. Como lugar de formação e informação, o livro infantil capacita o afloramento de uma visão de mundo inédita, onde a fantasia e as diferentes emoções entrelaçam-se, dialogam e entram em conflito, formando formas, normas e possiblidades de desenvolvimento cognitivo e afetivo. Por isso, é inquestionável, como aborda Franz (2001, p. 16), que "a literatura infantil é também ludismo, é fantasia, é questionamento, e dessa forma consegue ajudar a encontrar respostas para as inúmeras indagações do mundo infantil, enriquecendo no leitor a capacidade de percepção das coisas".

O livro infantil ao ser contemplado pela criança torna-se uma projeção da sua vida. Lá estão depositados todos os seus sentimentos, que, quando penetrados, revestem-se das possibilidades de conhecimento e reconhecimento de dificuldades, conflitos e decisões que precisam ser tomadas pela criança. E assim, recorremos ao que diz Meireles (1984, p. 128):

A natureza e intensidade dessas emoções podem repercutir na vida do pequeno leitor de maneira definitiva. Não apenas ele se lembrará, até a morte, desse primeiro encantamento, [...]; muitas vezes, a repercussão tem resultados práticos: vocações que surgem, rumos de vida, determinações futuras. 
Em nosso estudo, optamos pela exploração da literatura infantil, pois percebemos que o prazer de ler nesta idade é sobretudo motivado na exploração de livros paradidáticos. A prática pedagógica que faz uso do gênero literário propicia o despertar do prazer de ler, de imaginar mundos, acumulando bens culturais por intermédio da linguagem, transformando-se e ao mesmo tempo, o ambiente em que vive.

Também, nos incentivou a pesquisa, os comentários de Umberto Eco (1980) em seu texto "Mentiras que parecem verdades", quando o autor delata a existência de preconceitos e erros conceituais sobre as relações humanas, sociais e familiares que parece mostrar ao leitor infanto-juvenil muitos problemas e o faz de maneira equivocada. E será o que acontece com as relações de gênero? Que sentidos equivocados podem ser identificados nos paradidáticos em questão?

\section{Enunciação e discurso}

Ao consultar Michel Foucault (1995) em “Arqueologia do saber", por um lapso temporal, pensamos na impossibilidade de apresentar conceituações satisfatórias a respeito de enunciação e de discurso, haja visto a complexidade para um entendimento aprofundado e condizente com as defesas teórico-metodológicas a ser desencadeadas nesse estudo. Contudo, recorremos a Magalhães (2003), Fairclough (2001), Bakhtin (2004) e Verón (2004) no intento de apresentar de maneira mais didática esses conceitos.

Magalhães (2003, p. 33), trata enunciação como um processo, determinado por atos sociais que geram um universo discursivo e, em tempo, uma situação comunicativa. Apoia-se em Émile Benveniste (1989) e Osvald Drucrot (1987) para defender que enunciação refere-se à uma "substância de caráter referencial que submetida a certas regras de linguagem, cristaliza-se nas situações de comunicação, nas práticas discursivas do cotidiano. Realiza-se como ato social de fala, considerado sempre na sua singularidade, porque jamais se repete."

Para Verón (2004), a relação conceitual entre enunciação e enunciado é indissolúvel, pois imbricam-se na assertiva de que enunciação é da ordem do dizer e enunciado é da ordem do dito. Assim, como matéria enunciativa do discurso, é o enunciado, e como os modos de dizer, é a enunciação. Nesse contexto, enunciador e enunciatário, segundo Magalhães (2003), entrecruzam-se numa simbiose e semiose significantes, construindo representações de gênero em diversas plataformas midiáticas, das quais recortamos para o estudo, livros paradidáticos infantis.

Fairclough (2001) e Bakhtin (2004) também trazem contribuições para o conceito de enunciação. O primeiro valoriza a fala creditando-a acessibilidade e validade para estudos sistemáticos de correlação com variáveis sociais. Todavia, faz uma distinção: o ato de falar é individual, contudo, a fala é social, é compartilhada socialmente. Já Bakhtin 
(2004, p. 111) ao relacionar a enunciação com o ato da fala, também insere o aspecto social no processo, pois "Na realidade, o ato de fala, ou, mais exatamente, seu produto, a enunciação, não pode de forma alguma ser considerado como individual no sentido estrito do termo; não pode ser explicado a partir das condições psicofisiológicas do sujeito falante."

Quanto a discurso, pensamos demasiado importante considerar o que diz Foucault $(1995$, p. 90) sobre a unidade elementar do discurso, o enunciado.

[...] o enunciado aparece como um elemento último, indecomponível, suscetível de ser isolado em si mesmo e capaz de entrar em um jogo de relações com outros elementos semelhantes a ele; como um ponto sem superfície mas que pode ser demarcado em planos de repartição e em formas específicas de grupamentos; como um grão que aparece na superfície de um tecido que é o elemento constituinte; como um átomo do discurso. [...] o enunciado é a unidade elementar do discurso [...]

Para Fairclough (2001), que desenvolve sua defesa conceitual a partir de Michel Foucault, o discurso deve pensar o uso da linguagem como prática social, um modo de ação e representação, dialeticamente imbricado com a estrutura social. O discurso é constituído socialmente e moldado pela estrutura social. Relaciona-se com a linguagem a partir de três de suas funções: a identitária, a relacional e a ideacional. Por isso, para Norman Fairclough (2001), a prática discursiva é tributária da reprodução social, das identidades sociais, das relações sociais, dos sistemas de conhecimento e das crenças. Contudo, também é tributária da transformação social, materializada na forma linguística, como textos e imagens, como nos livros paradidáticos. Os eventos discursivos são práticas sociais, inclusive de consumo de mercadorias, serviços e cultura.

Nesse contexto, a partir de Magalhães (2003, p. 50), podemos entender o conceito de discurso como "[...] uma prática, ou mais especificamente, uma prática social na perspectiva de Foucault (1995, p. 51). [...] tanto pode ser uma obra completa, quanto uma lauda, um gesto, uma imagem ou uma única palavra”. Discurso é "[...] o uso da fala em situação de comunicação, o que acarreta implicações enunciativas”.

\section{Livro, imagem e gênero}

Como por inerente, mas não regrativo, as imagens quase sempre ocupam o lugar de destaque nos livros paradidáticos, que preenchidos com textos, desenhos, marcas, caricaturas, fotografias ou instantâneos testemunhais, indicam prévia e visualmente o que o enunciatário irá ouvir. Para Pinto (1999, p. 24), as imagens, da mesma forma 
que outros tipos de discursos sociais, “[...] têm papel fundamental na reprodução, manutenção ou transformação das representações que as pessoas fazem e das relações e identidades com que se definem uma sociedade". Nessa perspectiva, o autor defende que a imagem, como qualquer outro discurso, seria "[...] sempre um tecido de vozes ou citações, cuja autoria fica marcada ou não, vindas de outros textos preexistentes, contemporâneos ou do passado" (PINTO, 1999, p. 27).

A discussão contemporânea sobre as questões de gênero, e sobretudo dessas questões na literatura infantil, a muito não relacionam-se mais aos aspectos biológicos e dualizados entre homem e mulher. As representações de gênero que procuramos identificar nesse estudo tratam de como o masculino e o feminino se manifestam em produtos da prática pedagógica, os livros paradidáticos.

Descrever, interpretar e explicar relações de gênero em plataformas literárias é importante, pois assim é possível problematizar os papéis públicos destinados a homens e mulheres. Scott (1995) acredita na utilidade do conceito de gênero para a análise científica e histórica quando defende que a cultura em vigor constrói socialmente as qualidades de homens e mulheres, naturalizando os efeitos do patriarcado na compreensão de que a sociedade estaria estruturalmente equilibrada por meio de uma divisão social de papéis entre homens e mulheres. Notadamente, em inúmeros livros infantis, observamos, além da aceitação social, a construção social de comportamentos naturais relacionados a homens e mulheres, legitimando e sedimentando valores, ideologias e realidades sociais, através da linguagem da literatura infantil. Por isso, neste mesmo encadeamento lógico, acreditamos que os estereótipos de gênero manifestam-se socialmente, sobretudo, no texto literário e em todo o seu aparato semiótico. Portanto, corroboramos com Ribeiro (2006, p. 80) quando diz que:

As relações de poder entre homens e mulheres na família e na sociedade são práticas que se refletem na materialidade da linguagem. É o tecido social que oferece pistas, para que percebamos os mecanismos de cristalização de sentidos, cuja análise, atrelada à história de constituição discursiva, leva-nos a brechas, falhas e rupturas na contiguidade de sentidos.

\section{Corpus e análise}

Os estudos quem envolvem linguagem e significação necessitam de uma fundamentação teórico-metodológica para o seu desenvolvimento, por isso escolhemos a análise crítica do discurso (ACD) ${ }^{1}$, pois esta consegue,

\footnotetext{
1 Deste ponto em diante usar-se-á ACD para designar o termo Análise Crítica do Discurso.
} 
satisfatoriamente, desenvolvê-los, alcança dizibilidades relacionadas à ideologia e às relações de poder. A prática discursiva é fundamentada na intertextualidade, e, enquanto prática social, trata a linguagem como parte da sociedade, pois essa mesma linguagem é um processo social, não estando a sociedade à sua margem, mas no seu interior. Assim, a linguagem é condicionada socialmente, e nem sempre por vetores linguísticos (FAIRCLOUGH, 2001, p. 29-30).

Escolhemos a ACD pelo fato de que a análise dos livros paradidáticos adotados pela Escola Santa Helena se coaduna com os preceitos de Fairclough (2001) quando do entendimento de que textos são eventos sociais, inseridos em práticas sociais de linguagem que por sua vez pertencem a estruturas abstratas sociais, econômicas, políticas e culturais. Dizem respeito à própria linguagem, enquanto sistema de possibilidades. Portanto, as estruturas e as práticas sociais pertencem ao contexto de cultura enquanto que os eventos, refletidos nos textos, pertencem a um contexto situacional.

A pesquisa realizada envolve a análise das enunciações sobre gênero no suporte mais usando na prática pedagógica brasileira, o livro, especificamente, paradidáticos do $1^{\circ}$ ano de ensino fundamental. Essa análise envolve sobretudo o contexto de situação, as práticas sociais que envolvem o uso da literatura infantil. Portanto, em ACD não há como realizar análises textuais isoladas. Embora a análise parta de um corpus textual específico, ela sempre se remeterá as práticas sociais, sendo que o discurso, as representações linguísticas e semióticas, são apenas um momento desta complexa rede, no contexto cultural.

A utilização referencial teórica proposta por Norman Fairclough (2001) justifica-se pela crença que o discurso faz uso da linguagem como uma prática social, não sendo unicamente individual, pois é um modo de ação, "uma forma em que as pessoas podem agir sobre o mundo e especialmente sobre os outros, como também um modo de representação" (FAIRCLOUGH, 2001, p. 91).

Destarte, o desencadeamento analítico realizado é orientado pelo modelo tridimensional de Fairclough (2001) que reúne três pilares analíticos: a análise textual, a prática discursiva e a prática social, metodologicamente organizado em três momentos: 1) a descrição (apresentação das propriedades formais do texto, pois são plenas de sentido); 2) a interpretação (momento de relacionar textos com outros textos, em que percebe-se a formação do outro); e 3) a explicação (é a reflexão e exposição da análise realizada). 


\section{Descrição do corpus}

Os músicos de Bremen

O livro paradidático Os músicos de Bremen é um conto dos irmãos Grimm - Jacob e Wilhelm, recontado por Ruth Rocha, ilustrado por Cris Eich e publicado pela Editora Salamandra.

O enredo do conto baseia-se na ideia de que os animais (personagens) da história estão muito velhos e não conseguem mais servir aos seus donos, que querem livrar-se deles, inclusive, intentando a morte. Por isso, o burro, o cão, o gato e o galo fogem de seus donos, indo para a cidade de Bremen, sonhando em tocar numa fanfarra local. Sonho e necessidade de sobrevivência fizeram-lhes marchar juntos, quando no meio do caminho encontraram uma casa de ladrões e logo planejam afasta-los de lá para tomar seus lugares, ter dormida e comida. Organizam uma fanfarra onde

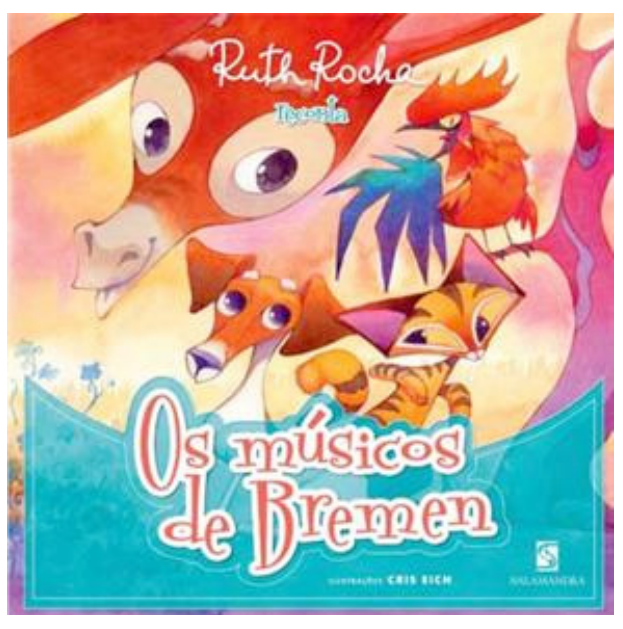
o burro zurra, o cão uiva, o gato mia e o galo canta, numa mistura de sons destinados a assustar os malfeitores. A aparição e a cantoria repentina os transformam num "fantasma" assustador que expulsa os ladrões da casa.

Os malfeitores voltam ao esconderijo, avistam a casa em silêncio e escura, e um deles foi verificar se o fantasma tinha ido embora. Ao entrar é atacado pelo gato, pelo cão, pelo burro e pelo galo, que foram perturbados do sono tranquilo. O ladrão associa-os a imagens tenebrosas: uma bruxa, um homem mau, um monstro negro e um juiz; uma recriação da fanfarra que os animais desejavam fazer.

Os quatro músicos não foram à Bremem, ficaram no local onde a vida lhes deu a resposta aos seus sonhos, suas vidas ganharam um novo sentido e viveram felizes para sempre.

Ao analisar o conto, percebemos que os quatro animais, seus donos e os ladrões são do gênero masculino. A única exceção é a dona do gato. Os donos dos animais são tratados como "amos" e apresentados sempre como pessoas más que querem se livrar dos animais que não mais os servem. Assim como os ladrões que também são do gênero masculino e assumem uma simbologia dicotômica do "mau". Percebemos, também uma estreita relação intertextual entre ser velho e ser inservível, entre a fuga da morte e a utopia de serem músicos, todavia, não percebem-se opções, mas quase enxerga-se a falta delas.

Chamou-nos atenção seletiva o fato de quatro aninais de natureza tão diferentes encontrarem consenso, unicidade de sonhos e espírito coletivo para atingir o objetivo de participarem de uma fanfarra. Daí, indago: Por que ainda tanta binaridade nas relações de gênero? Complexificá-las numa direção complementar não seria uma inspiração do enredo deste conto? Enfim, analogia, talvez desconexa, mas disparadora de uma possível reflexão. 
Referendar o gênero masculino como "malfeitor" é um propósito do texto em sua nuance descritiva, pois "amos" e ladrões assim foram pincelados, contudo, burro, cão, gato e galo, também do gênero masculino, foram apresentados como mocinhos, sonhadores, perseverantes e astutos, revelando dois esteriotipais masculinos, fazendo preencher uma narrativa de ausência de feminilidades.

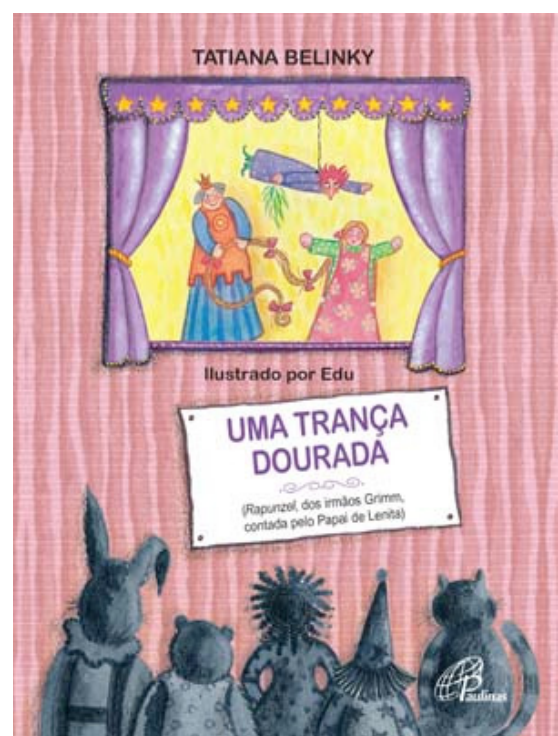

Uma trança dourada, de Tatiana Belinky, é um livro paradidático que traz a magia e o encanto dos clássicos contos de fadas. Faz parte de uma coleção "Tapete de histórias", da editora Paulinas. Trata-se do clássico Rapunzel, recontado por Tatiana Belinky e ilustrado por Edu, em que a autora inventa uma menina, a Lenita, que toda noite aguarda seu pai para ouvir uma história. No enredo, Rapunzel já tinha seu destino traçado, antes mesmo de nascer. Ela era prometida a uma bruxa para salvar a vida de seus pais. Foi trancada em uma torre sem escada e sem porta, recebia somente a visita da bruxa até o dia em que um príncipe, não resistindo ao encanto de sua voz, resolveu conhecê-la, ousadia essa que lhe custou os olhos e o amor de Rapunzel, que ao final, com suas lágrimas, cura-o da cegueira. E é desta forma que Tatiana Belinky encerra o conto, com Lenita adormecendo, em mais uma noite mágica.

A rainha rabiscada de Sylvia Orthof, conta a história de uma rainha que com muita simpatia, desenhava tudo que vinha à sua mente. A cada vontade sentida, um desenho materializado. A Rainha do lápis, que com imensa capacidade de criação, fazia muitas estripulias. Quando ela não gosta do que fez, apaga e desenha tudo de novo. Desenhou um avião e foi até Brasília. Ao chegar ao seu destino, apaga o ministro que havia roubado dinheiro do povo. Aproveita a viagem também para apagar alguns deputados safados. Sua vida é um interminável desenhar e desenhar... apagar e desenhar tudo de novo.

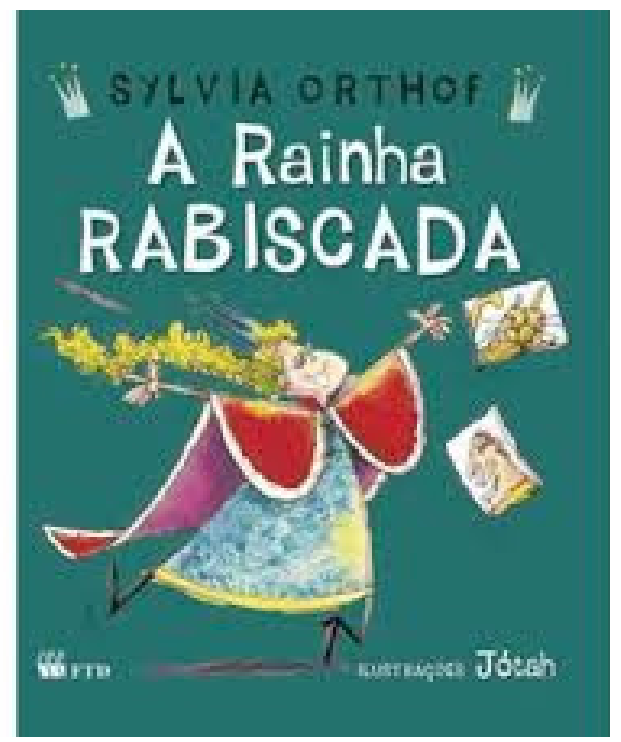


O pavão do abre e fecha, de Ana Maria Machado, conta a história de um pavão viva um dilema sobre ser feio ou bonito. Gostava de ver-se com a cauda aberta, em contrapartida, seu andar desajeitado e seus pés não lhes agradava. Durante a história relaciona-se com um pombo-correio, um pardal, um periquito, e um casal de urubus que reforçam a importância de sua presença na festa e lhes dão força para ficar feliz. Já o tangará e o bem-te-vi sorriem de sua forma de dançar e da falta de sua pena, prevendo uma festa divertida pelo desengonço do pavão. Durante os ensaios da dança o pavão perde uma de suas penas do lado direito e fica muito triste, e duvidoso de sua beleza e de sua presença na festa, contudo, ao final percebe que beleza depende do ponto de vista de cada um e de que sua autoestima era o mais importante.

\section{Interpretação e explicação}

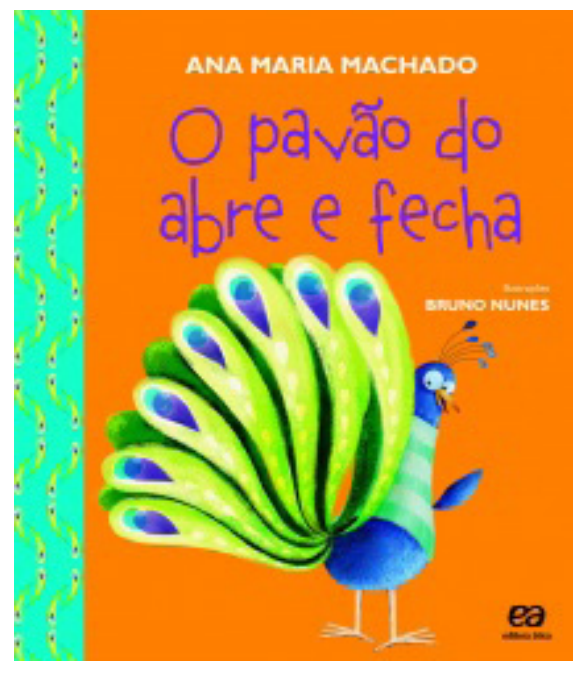

Os livros paradidáticos apresentados reforçam um conjunto literário que segundo Calvino (1993, p. 10), "constituem uma riqueza para quem os tenha lido e amado; mas constituem uma riqueza não menor para quem se reserva a sorte de lê-los pela primeira vez nas melhores condições para apreciá-los.” Daí, a importância de serem trabalhados ainda no primeiro ano do ensino fundamental.

Furlani (2005) e Pires (2009) atentam para a importância de discutir criticamente e problematizar a forma como os livros são trabalhados nas escolas, pois uma abordagem equivocada reitera modelos normativos, ensina e prescreve modos de agir, como no caso dos padrões de gênero. Dessa forma, ao analisar os textos e redirecionar o olhar para as questões de gênero enquanto categoria de análise, percebemos a necessidade de observar como as enunciações de gênero são abordadas na literatura infantil, pois percebemos que as representações simbólicas sobre o que "adequado" e "desejável" inicia-se na infância.

Alguns não ditos textuais que induzem à binaridade sexual puderam ser observados nos livros como o urubu de gravata e a urubua de laço e tiara rosa, no livro O pavão do abre e fecha, as meninas de rosa e mulheres de saias rodadas, homens de calças e camisas de botão, em a Rainha Rabiscada, além dos grandes vestidos da bruxa e da Rapunzel, e do quarto com ursinho de pelúcia e boneca de Taline, e de seu pai com um grande bigode e camisa de botões e manga longa, em a A Trança Dourada. Ou seja, coisas de menino, e coisas de menina. 
Alguns comportamentos também denotam essa bipartição sexual: os ladrões são maus, assim como os donos dos animais em Os Músicos de Bremem; O pavão que gosta de exibir suas imponentes penas e quando isso não acontece este se cai em tristeza, em O pavão do abre e fecha; A garota Taline, meiga, singela, ingênua e amorosa, que apresenta-se como uma forma materializada da personagem de Rapunzel, em A trança dourada; e o recomeço da vida que é representado pelo nascimento de um pinto, em A rainha rabiscada.

Esses esteriotipais sexualizados apresentam formas de comportamento que denotam atividades masculinas e femininas, contexto este que faz parte de todo um aparato histórico cultural que construiu e vem construindo a definição de gênero em nossa sociedade. Assim, percebemos a lei biológica, heteronormativa, ainda prevalente no material pesquisado.

Por heteronormatividade, Louro (2009) define como a heterossexualidade como única, normal, saudável e desejável forma de exercício da sexualidade, pois todo diverso, também é anti-natural, anormal e desviante. E essa perspectiva perpassa toda a bibliografia abordada, pois não percebemos nenhum personagem diverso do ponto de vista da heterossexualidade.

Os padrões de gênero são construídos socialmente e reiterados pelos mais diversos aparatos comunicacionais, dentre os quais a literatura infantil e os livros didáticos não se distanciam. Aliados à família, aos meios de comunicação e a outras instituições como a igreja, os padrões de gênero vão se conformando segundo o exercício dos campos de força desses instituintes das representações de gênero.

Nos livros analisados, observamos um conjunto de aspectos diversos como atitudes, linguagem, vestimentas, brinquedos, que, uma vez expressados no comportamento dos adultos, familiares e da sociedade, de um modo geral, contribuirão para a consolidação da construção das representações de gênero na criança que dela faz parte (FURLANI, 2005).

Diversos artefatos culturais puderam ser observados durante a exploração do corpus textual e imagético como bonecas, ursinhos, varinha, chapéus, vestimentas, profissão, edificações, lugar, expressões corporais e faciais, cores, formas, instrumentos de profissão, lazer e diversão e, a partir dessas vizibilidades pudemos olhar por um viés crítico os constructos representacionais de gênero. E encontramos alicerce conceitual para o que observamos em Pires (2009, p. 168) que encontrou também em suas pesquisas aparatos semióticos em que

[...] o masculino e o feminino são representados na maior parte das imagens de uma única forma, mostrando, de maneira geral, o homem como energético, forte, racional, ousado, atrevido e a mulher como passiva, frágil, sentimental, doméstica e comportada. Essa forma de referir-se à mulher pode ser vista principalmente na representação visual das mães, pois elas são talhadas como exemplos de proteção, carinho e ternura. Comumente é associada a imagens femininas uma idéia (sic) leve, suave, meiga, comportada, como o tipo ideal de feminilidade [...]

Educação Por Escrito, Porto Alegre, v. 7, n. 2, p. 263-277, jul.-dez. 2016 
Como visibilidades, ainda chamamos atenção para as invisibilidades da literatura infantil que reduzem as relações entre os sexos ao paradigma biologizante que serve-se do fenômeno da reprodução para legitimar seu fundamento. E nesse processo, percebemos a materialização da incerteza que move os discursos, da variabilidade interpretativa que é fundamentada numa recepção ativa, que possibilita a construção de uma subjetividade potente, desde a infância. Pena que a orientação dos campos de força (Bourdieu, 1999) que circunscrevem a mulher como detentora e um lugar nada privilegiado (violência doméstica) como o doméstico, o romântico, o ingênuo, o emocional, observado em A trança dourada, O pavão do abre e fecha, e na invisibilidade dessa em Os músicos de Bremem. Nesse, a binaridade sexual é ativa, preservada, pois a reprodução de papéis afirma a tal docilidade que seria inerente ao feminino. Aos homens, nesse modelo, corresponde a atividade e a força, e, às mulheres, a debilidade e passividade. E assim, reforçamos nosso entendimento com o que diz Gens (2008, p. 59) sobre os paradidáticos de educação infantil:

São esses livros que estão nas mãos de crianças e jovens e formam leitores, e mais do que isso, sinalizam para condutas, comportamentos e pensares. Alguns deles estimulam, por vezes, reflexões, potencializam atos de ser, outros param na simples exposição, outros, ainda, deixam perceber preconceitos e fossilizações. Muitos trazem representações de meninas agarradas à domesticidade e ao espaço privado, definidas pela tecnologia de gênero e engendradas nas relações sociais, em que parece não haver espaço para mudanças e escolhas. Outras deixam entrever modulações e deslizamentos, levando, ao menos, a uma desestabilização das condutas fossilizadas. Será possível reemoldurar, ou até mesmo viver sem molduras e enquadramentos? Se não, que seja afiançada, pelo menos, a possibilidade de desnaturalizar as marcas de gênero, mostrando o que elas apresentam de forçado e estático, e como são vendidas aparentemente fazendo parte da natureza do humano. Dentro dessa perspectiva, não se pode esquecer que a formação literária de crianças e adolescentes acontece por intermédio, principalmente, de textos de ficção. Por meio deles, leitoras e leitores têm acesso a universos conhecidos e desconhecidos, vêem-se frente a heróis e vilões, entram em contato com cotidianos em que ser menina ou menino aparece como uma pré-figuração, muitas vezes. Do mapeamento de obras empreendido neste trabalho, restou um traçado ziguezagueante, não retilíneo, que provoca o movimento de pensar a produção para crianças e jovens nesse início do século. E, também, permite refletir sobre o que pode ser demarcado em questões de gênero. Nesse quadro legível, organizam-se movimentos, travessias, negociações de sentido e matiza-se a complexidade da construção do sujeito.

$\mathrm{Na}$ pesquisa, encontramos uma construção discursiva de relações de gênero que privilegia hierarquias, que privilegia estratégias de dominação e desigualdades, contudo, também encontramos relações de igualdade como é 
no livro A rainha rabiscada, quando da relação hierárquica entre um casal de marido e mulher em que o marido passa roupa enquanto a mulher fica deitada, mas que depois a rainha apaga esse contexto e desenha então os dois dividindo as tarefas domésticas. Todavia, corroboramos com Gens (2008) quando refere que nos livros paradidáticos infantis, os postulados androcêntricos ainda se situam muitas vezes como matriz, seja latente ou manifesta, na pauta da exploração do tema que situa comportamentos de meninas e meninos na literatura infanto-juvenil. O exercício de leitura é, no entanto, ato de potência. E exercendo-o, através da consciência, traçam-se os caminhos que permitem a distinção entre a opressão e a resistência, entre a dominação e o agenciamento. Desestabilizar as representações, redefinir o gênero, para além dos liames sexuais, em novas perspectivas, é a tarefa, em constante exercício de compreender o mundo e, pelo menos, tentar mudá-lo.

\section{Considerações finais}

A partir deste estudo, concluímos que padrões definidores de normalidade entre os sexos é reforçado na literatura infantil adotada pela Escola Santa Helena no ano de 2014 para o primeiro ano da educação infantil. As representações de um gênero masculino mau, príncipe, exibicionista, político, e de um gênero feminino singelo, mágico (fada), mocinha, princesa/rainha, acompanhante do marido e dona de casa estão implícita e explicitamente reproduzidos nos livros analisados, apesar da identificação de abordagens isoladas como no caso do livro A rainha rabiscada.

Percebemos, em acordo com Furlani (2005) que o conteúdo dos livros paradidáticos constrói representações de masculino, feminino, de modos de agir, da sexualidade, e estas acabam por assumir um efeito de verdade. E, por isso, não podem ser utilizados sem uma reflexão crítica, sob pena de tornarem-se reforçadores de estereótipos do que parecem esclarecer, em detrimento de uma educação de caráter emancipatório, que possibilite a discussão, a desconstrução de padrões hegemônicos e a criação de novos paradigmas de gênero.

Sabemos que os sujeitos (nesta pesquisa, as crianças) são subjetivados pelos discursos que circulam na literatura adotada para a educação infantil, expressando dinâmicas de exercício de poder que homogeneíza, diferencia e marginaliza via práticas discursivas a que estes sujeitos são submetidos.

Apesar da problemática em se usar os termos "masculino" e "feminino" (Bluter, 2003), concluímos que as abordagens discursivas dos quatro livros paradidáticos analisados direcionam-se a um contexto em que um poder disciplinar que objetiva reforçar normas de condutas de meninos e meninas onde a hipervalorização da masculinidade e a celebração da heteronormatividade engendram um campo de forças onde tudo o que não se coaduna com determinados padrões é desviante. 
O processo de construção de representações de gênero em livros paradidáticos é sutil, quase imperceptível se não se olhar sobre a égide crítica, pois roupas, cores, palavras e atitudes são atribuídos a normalizações de gênero, quase sempre assimétrica e vertical, tendo a masculinidade em voga.

\section{Referências}

BAKHTIN, M. M.; VOLOSHINOV, V. N. Marxismo e filosofia da linguagem: problemas fundamentais do método sociológico nas ciências da linguagem. 11. ed. São Paulo: Hucitec, 2004.

BENVENISTE, E. Problemas de linguística geral II. 2. ed. Campinas: Pontes, 1989.

BOURDIEU, Pierre. A dominação masculina. Rio de Janeiro: Bertrand Brasil, 1999.

CALVINO, Ítalo. Por que ler os clássicos. Trad. de Nilson Moulin. São Paulo: Cia. das Letras, 1993.

DUCROT, Osvald. O dizer e o dito. Campinas: Pontes, 1987.

ECO, Umberto. Mentiras que parecem verdades. São Paulo: Summus, 1980.

FAIRCLOUGH, Norman. Discurso e mudança social. Brasília: Editora UnB, 2001.

FOUCAULT, Michel. A arqueologia do saber. 4. ed. Rio de Janeiro: Forense Universitária, 1995.

FRANTZ, Maria Helena Zancan. O ensino da literatura nas séries iniciais. 3. ed. Ijuí, RS: Editora UNIJUI, 2001.

FURLANI, Jimena. O bicho vai pegar! - um olhar pós-estruturalista à educação sexual a partir de livros paradidáticos infantis. Tese (Doutorado) - Programa de Pós-Graduação em Educação, Universidade Federal do Rio Grande do Sul, Porto Alegre, 2005.

GENS, Rosa. Menina ou menino? gênero na literatura para crianças e jovens. Revista Forum Identidades, ano 2, v. 4, p. 51-61, jul.-dez. 2008.

LAJOLO, Marisa. Do mundo da leitura para a leitura do mundo. 6. ed. São Paulo: Ática. 2008.

LOURO, Guacira Lopes. Gênero, sexualidade e educação: uma perspectiva pós-estruturalista. Petrópolis: Vozes, 2003.

LOURO, Guacira Lopes. Heteronormatividade e homofobia. In: JUNQUEIRA, R. D. (Org.). Diversidade sexual na educação: problematizações sobre a homofobia nas escolas. Brasília: Ministério da Educação, Secretaria de Educação Continuada, Alfabetização e Diversidade, Unesco. 2009. p. 85-93. (Coleção Educação para todos, 32).

MAGALHÃES, Francisco Laerte Juvêncio. Veja, Isto é, Leia. a imagem e a imagem nos discursos de capas das revistas Veja e Isto é; produção e disputas de sentido na mídia. Teresina: EDUFPI, 2003. 158 p.

MEIRELES, Cecília. Problemas da literatura infantil. 3. ed. Rio de Janeiro: Nova Fronteira, 1984.

PINTO, Milton José. Comunicação e discurso: introdução à análise de discursos. São Paulo: Hacker, 1999. 123 p. 
PIRES, S. M. F. Histórias de amor para sempre, histórias de amor para nunca mais...: o amor romântico na literatura infantil. 2009. 176 f. Tese (Doutorado) - Programa de Pós-Graduação em Educação, Universidade Federal do Rio Grande do Sul, Porto Alegre, 2009.

RIBEIRO, Manoel P. Feminismo, machismo e música popular brasileira. Revista Eletrônica do Instituto de Humanidades, v. 5, n. 19, p.73-83, out.-nov. 2006.

SCOTT, Joan Wallach. Gênero: uma categoria útil de análise histórica. Educação \& Realidade, Porto Alegre, v. 20, n. 2, p. 71-99, jul.-dez. 1995.

VERÓN, Eliseo. Fragmentos de um tecido. São Leopoldo, RS: Editora Unisinos, 2004.

Recebido em: abril/2016

Aceito em: novembro/2016

Endereço para correspondência:

Fábio Soares da Costa

Av. Ipiranga, 6681 - Prédio 15

90619-900 Porto Alegre, RS, Brasil

$<$ fabiosoares.com@hotmail.com> 